\title{
CRANIOMANDIBULAR OSTEOPATHY IN A BULGARIAN SHEPHERD DOG - CASE REPORT
}

\author{
S. Krastev ${ }^{1}$, R. Simeonov ${ }^{2}$, N. Goranov ${ }^{1}$ \\ ${ }^{1}$ Department of Veterinary Surgery, Faculty of Veterinary Medicine, Trakia University, Stara Zagora, \\ Bulgaria \\ ${ }^{2}$ Department of General and Clinical Pathology, Faculty of Veterinary Medicine, Trakia University, \\ Stara Zagora, Bulgaria
}

\begin{abstract}
A 8-month-old male Bulgarian Shepherd dog was presented with bilateral hot and painful swelling of the mandible and progressively decreased joint mobility. The dog could not open its mouth, and had a onemonth history of permanent salivation and difficulty to eat. The applied treatment with corticosteroids for about 3 weeks did not improve the patient's condition. Craniomandibular osteopathy was diagnosed based on skull radiographs and histological findings from bone samples after necropsy.
\end{abstract}

Key words: Craniomandibular Osteopathy, Bulgarian Shepherd Dog, Dog.

\section{INTRODUCTION}

Craniomandibular osteopathy $(\mathrm{CMO})$ is a rare disorder in young dogs, characterised with bilateral coarse bone proliferative disorders which typically affect mandibular ramus, angle and the ear pyramid. Occasionally, the bone remodelling could involve other bones of the skull (maxilla, frontal and parietal bones) as well as appendicular bones (radius, ulna etc.) $(1,2,3,4)$. The disease is not of neoplastic nature (5) and does not threaten life. Usually, $\mathrm{CMO}$ becomes a problem at a specific stage of growth of affected animals because of the formation of solid painful swellings in the temporomandibular space, limited motility of mandibular joints and inability for normal feeding and drinking. The clinical manifestations in such patients are constant salivation, anorexia, painful passive opening of the mouth (6). Sometimes, bone irregularities could be palpated. The routine haematological and blood biochemical analysis are not reliable in diagnosing the disease (7).

The majority of affected dogs are 3-8 months of age, from Scottish terrier, West highland white terrier, Boston terrier and Cairn terrier breeds (2). Less frequently, CMO is reported in

\footnotetext{
*Correspondence to: Dr. Svetozar Krastev, Department of Veterinary Surgery, Faculty of Veterinary Medicine - Trakia University, 6000 Stara Zagora, Bulgaria; tel 042-699-662; e-mail: sgk_vet@abv.bg
}

Bullmastiff (8), Labrador retriever $(9,10)$, Great dane (11), Doberman pinscher (1), Boxer (12), Shetland sheepdog (13), Pyrenean mountain breed (14), English bulldog (15) and Akita (16).

CMO etiology is not sufficiently clear, but a genetic predisposition is suggested. It is affirmed that in terriers, the disease is transmitted through an autosomal recessive gene (17). Other studies have outlined the effects of infectious agents (Escherichia coli, canine distemper virus), especially when the manifestations are accompanied by an intermittent fever at 2-4 week intervals $(18,19)$. Hence, in most instances, CMO is diagnosed in the basis of specific radiological signs and corresponding histopathological findings. From differential diagnostic point of view, aseptic or infectious osteomyelitis, traumatic periostitis, metabolic and neoplastic diseases of skull bones should be considered.

To the best of our knowledge, no description of the disease in Bulgarian Shepherd dog is available.

\section{CASE HISTORY}

A male Bulgarian Shepherd dog, 8 months of age, weighing $28 \mathrm{~kg}$ was referred to the Small Animal Clinic at the Faculty of Veterinary Medicine - Trakia University - Stara Zagora. The physical examination revealed a massive bilateral hot and hard swelling in the region of 
the mandible of one month history. During that time, mandibular motility has progressively decreased, and at a later stage, pain during passive opening of the mouth and permanent salivation have appeared. Antibacterial and anti-inflammatory drugs have been applied with various success.

At the time of the physical exam, rectal body temperature was slightly increased $\left(39.8{ }^{\circ} \mathrm{C}\right)$. The results from CBC and blood biochemical analysis are presented in Table $\mathbf{1 .}$

Table 1. Results from CBC (Serono 150 plus, Germany) and blood biochemical analysis (BA88 Mindray, China) of the CMO patient

\begin{tabular}{|l|l|l|}
\hline $\begin{array}{l}\text { Morphological } \\
\text { parameter }\end{array}$ & $\begin{array}{l}\text { Detected } \\
\text { value }\end{array}$ & $\begin{array}{l}\text { Reference } \\
\text { values }\end{array}$ \\
\hline $\mathrm{Hg}, \mathrm{g} / \mathrm{L}$ & 120 & $120-180$ \\
$\mathrm{PCV}, \mathrm{l} / \mathrm{l}$ & 0.38 & $0.37-0.55$ \\
$\mathrm{RBC}, \mathrm{T} / \mathrm{L}$ & 5.62 & $5.5-8.5$ \\
$\mathrm{MCV}, \mathrm{fl}$ & 60.8 & $60-77$ \\
$\mathrm{WBC}, \mathrm{G} / \mathrm{L}$ & 14.3 & $6-17$ \\
$\mathrm{Sg}, \mathrm{G} / \mathrm{L}$ & 6.616 & $3.6-11.5$ \\
$\mathrm{Bands}, \mathrm{G} / \mathrm{L}$ & 0.282 & $0-0.3$ \\
$\mathrm{Mm}, \mathrm{G} / \mathrm{L}$ & 0.188 & 0 \\
$\mathrm{M}, \mathrm{G} / \mathrm{L}$ & 0 & 0 \\
$\mathrm{Eo}, \mathrm{G} / \mathrm{L}$ & 0.376 & $0.01-1.25$ \\
$\mathrm{Ba}, \mathrm{G} / \mathrm{L}$ & 0 & $0-0.1$ \\
$\mathrm{Ly}, \mathrm{G} / \mathrm{l}$ & 2.256 & $1-4.8$ \\
$\mathrm{Mo}, \mathrm{G} / \mathrm{L}$ & 0.252 & $0.15-1.35$ \\
\hline Biochemical & Detected & Reference \\
parameter & value & values \\
\hline Total protein, g/L & 66 & $51-72$ \\
$\mathrm{ALAT}, \mathrm{U} / \mathrm{L}$ & 16 & $19-59$ \\
$\mathrm{ASAT}, \mathrm{U} / \mathrm{L}$ & 25 & $20-50$ \\
$\mathrm{Ca}, \mathrm{mmol} / \mathrm{L}$ & 2.52 & $2.4-2.8$ \\
$\mathrm{P}, \mathrm{mmol} / \mathrm{L}$ & 1.66 & $0.94-1.52$ \\
$\mathrm{Mg}, \mathrm{mmol} / \mathrm{L}$ & 1.01 & $0.6-1.1$ \\
\hline
\end{tabular}

Radiography of the mandible in two standard views (Figures 1 and 2) revealed extensive bilateral coarse periosteal proliferation affecting irregularly the proximal mandibular angles and rami, causing ankylosis of temporomandibular joints and reaching the tympanic bulla. The newly grown bone tissue was visualised with a strong radiopaque shadow, without distinct margins between cortex and medulla. The teeth were normal, but exhibited substantial symmetric bone loss in the rostral part of the surrounding bone. Soft tissues in this regions also seemed thickened.

A therapy with Dexamethasone $0.2 \%$ (Alfasan International B.V.) at $0.5 \mathrm{mg} / \mathrm{kg}$ i.m. for 3 days, followed by Prednisolon Cortico (Balkanpharma - Razgrad Ltd) at a daily dose of $0.5 \mathrm{mg} / \mathrm{kg}$ p.o. for 7 days was prescribed, followed by a second 14-day course with the same dose, but applied every other day. As a result of the treatment, swelling and salivation resolved during the first 3-4 days, but joint motility remained limited.

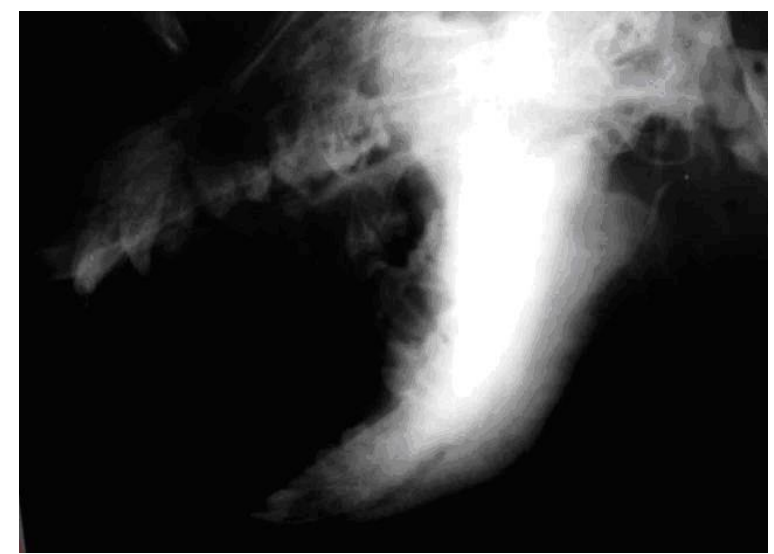

Figure 1. Lateral view of the mandible in a dog with CMO (TUR D-800, Germany; 60 kW, 10 mAs).

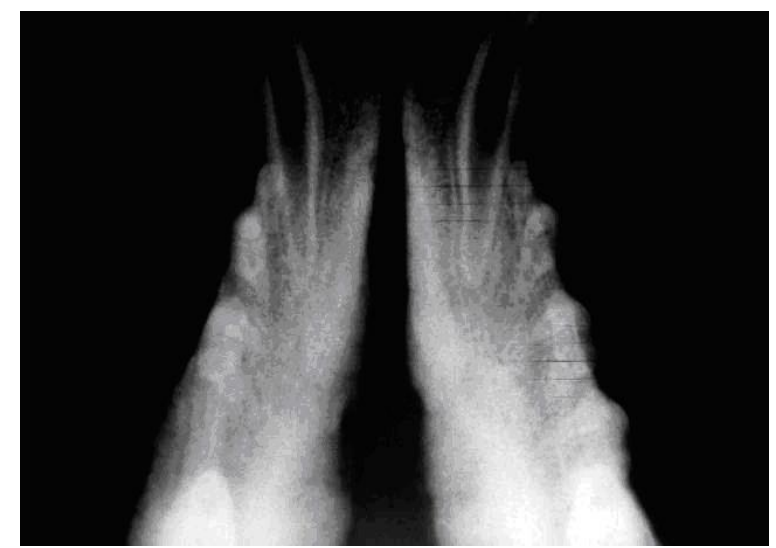

Figure 2. Intraoral ventrodorsal view of the mandible in a dog with CMO (TUR D-800, Germany; $60 \mathrm{~kW}$, $10 \mathrm{mAs}$ ).

On the $21^{\text {st }}$ day, the disease recurred, with progressive bilateral painful swelling, salivation, permanent temporomandibular joint immobilisation and inability for eating and drinking. After evaluation of the objective status of the patient and after obtaining informed consent from owners, the dog was euthanised.

Biopsy specimens were obtained from affected bone areas for histopathological examination. They were fixed in $10 \%$ neutral formalin, decalcified in $7 \%$ nitric acid for 3 days. Finally, the specimens were routinely stained with haematoxylin/eosin and observed under oil immersion.

Histopathological findings consisted in diffuse osteoclastic resorption of lamellae bone and profuse proliferation of coarse bone trabeculae (Figure 3). Bone proliferation resulted in enlargement of mandibular bones and replacement of medullary canal with fibrous vascular stroma. It contained mixed cell infiltratates from neutrophils, lymphocytes and plasma cells (Figure 4). 


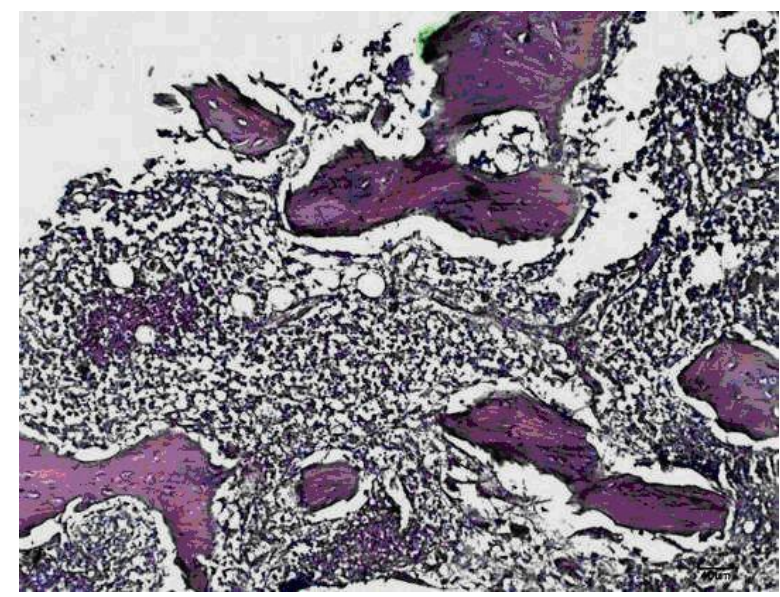

Figure 3. Craniomandibular osteopathy. Osteoclastic resorption of lamellar bone and its replacement with coarse bone trabeculae.

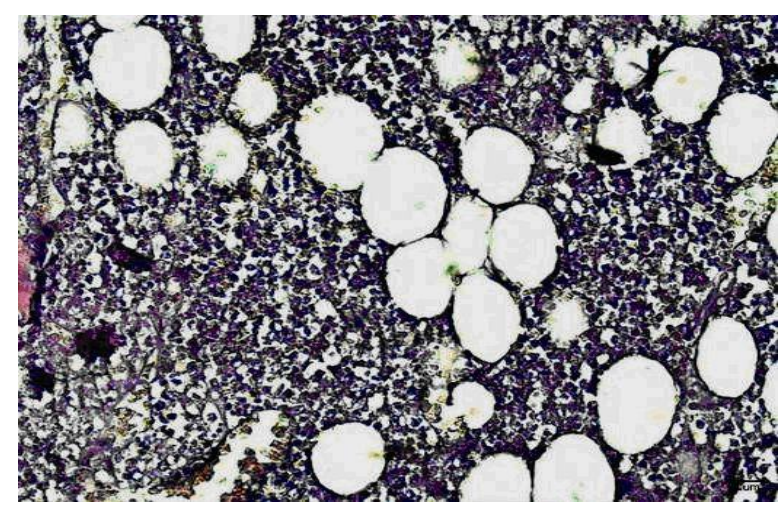

Figure 4. Craniomandibular osteopathy. The bone medullary canal with fibrous vascular stroma of mixed cell infiltrates.

\section{DISCUSSION}

The considerable variety of breeds affected occasionally by CMO without history of another disease suggests the dominating role of autosomal genetic inheritance of the disorder, while the involvement of sporadic factors (e.g. infectious) is rather a theoretical option (20).

The progression of CMO is disputable. The predominant opinion is that the disease is selflimiting with time, as its progression slows down and stops with age, although in some patients the bone disturbances are so extensive that the only outcome is euthanasia $(2,13)$. In other cases, the newly formed bone undergoes remodelling and becomes spontaneously smooth, allowing the jaw to regain a near-tonormal appearance $(11,17)$.

Most researchers agree that the reasonable use of non-steroid anti-inflammatory drugs and corticosteroids for CMO therapy could be beneficial for controlling the pain, fever and tissue swelling. Such treatment could improved the quality of life, allowing the patient to eat and drink, although it does not cure the disease $(19,20)$.
The attempts for surgical treatment for removing the bone mass in the temporomandibular joint to improve its motility are rarely successful (12).

An interesting fact from the interpretation of histological changes related to bone cells remodelling and perishing is that manifestations of inflammation in CMO are relatively frequent, so it could suggested as a triggering factor for initiation of the disease (19).

\section{CONCLUSION}

Craniomandibular osteopathy is a serious problem both for dogs and their owners. The prescribed therapy leads to short-time improvement of the quality of life but does not cure the disease. Only in very few cases, CMO could regress by the end of the bone growth period with normalisation of joint motility.

Neither surgical intervention, nor permanent gastrostomy are options of choice in advances cases as they do not present any advantage for survival of patients.

It could be therefore affirmed that the best therapy for canine CMO is the prevention at the time of selection and breeding of a given breed.

\section{REFERENCES}

1. Alexander, J. W. and Kallfelz, F. A., A case of craniomandibular osteopathy in a Labrador Retriever. Vet Med Small Anim Clin, 70:560-563, 1975.

2. Alexander, J. W., Selected skeletal dysplasias: craniomandibular osteopathy, multiple cartilaginous exostoses, and hypertrophic osteodystrophy. Vet.Clin.North Am. Small Anim Pract, 13:55-70, 1983.

3. Battershell, D., Craniomandibular osteopathy. JAVMA, 155:1735-1736, 1969.

4. Burk, R. L. and Broadhurst, J. J., Craniomandibular osteopathy in a Great Dane. J Am Vet Med Assoc, 169:635-636, 1976.

5. Franch, J., Cesari, J. R., Font, J., Craniomandibular osteopathy in two Pyrenean mountain dogs. Vet Rec, 142:455459, 1998.

6. William, O. R., Mathieu, M. G., Elizabeth, A. D., Marc, E. H., Craniomandibular osteopathy with a unique neurological manifestation in a young Akita. $J$ Am Anim Hosp Assoc, 47:7-11, 2011.

7. Fungfuang, W., Roongsuriyasipa, P., Tongyuan, S., Chakornmettagul, N., Tangkabadee, R., Mueanklaewklavichit, N., Surinkul, S., Kunakornsawat, S., Case report: Craniomandibular Fsteopathy in 
American Pit Bull Terrier in Thailand. Kasetsart Vet, 18(1):201-205, 2008.

8. Halliwell, W.H., Tumours-like lesions of Bone: In: Bojrab M J, Pathophysiology in Small Animal Surgery. Lea\&Febiger, Philadelphia, pp 716-728, 1981.

9. Hathcock, J. T., Craniomandibular osteopathy in an English Bulldog. J Am Vet Med Assoc, 181:389, 1982.

10.Munjar, T. A., Austin, C. A., Breur, G. J., Comparison of risk factors for hypertrophic osteodystrophy, craniomandibular osteopathy and canine distemper virus infection. Vet Comp Orthop Traumatol, 11:37-43, 1998.

11.Padgett, G. A. and Mostosky, U. V. Animal model: The mode of inheritance of craniomandibular osteopathy in West Highland White Terrier Dogs. Am J Med Genet, 25:9-13, 1986.

12.Pool, R. R. and Leighton, R. L., Craniomandibular osteopathy in dogs. $J \mathrm{Am}$ Vet Med Assoc, 154:675, 1969.

13.Riser, W. H., Parkes, L. J., Shirer, J. F., Canine craniomandibular osteopathy. $\mathrm{J} \mathrm{Am}$ Vet Radiol Soc 8:23-31, 1967.
14.Schulz, S., A case of craniomandibular osteopathy in a Boxer. J Small Anim Pract, 19:749-757, 1978.

15.Taylor, S. M., Remedios, A., Myers, S., Craniomandibular osteopathy in a Shetland sheepdog. Can Vet J, 36:437-439, 1995.

16.Watkins, J. D. and Bradley, R., Craniomandibular osteopathy in a Labrador puppy. Vet Rec, 79:262-264, 1966.

17.Watson, A. D. J., Adams, W. M., Thomas, C. B., Craniomandibular osteopathy in dogs. Compend Contin Educ Pract Vet, 17:911922, 1995.

18.Watson, A. D. J., Huxtable, C. R. R., Farrow, B. R. H., Craniomandibular osteopathy in Doberman pinschers. J Small Anim Pract , 16:11-19, 1975.

19.Riser, W. H. and Newton, C. D., Craniomandibular Osteopathy. In: Newton C D, Numaker D M (eds), Textbook of Small Animal Orthopaedics, Lippricott Co Philadelphia, PA, USA, ch. 54, pp 621-626, 1985.

20.Huchkowsky, S. L., Craniomandibular osteopathy in a bullmastiff. Can Vet J, 43:883-885, 2002. 